\title{
Descriptive osteology of fishes referred to the genus Rasboroides Brittan (Teleostei: Cyprinidae)
}

\author{
S. Batuwita ${ }^{*}$, S. Udugampala ${ }^{1}$, S. Athauda ${ }^{2}$ and U. Edirisinghe ${ }^{2}$ \\ Postgraduate Institute of Agriculture \\ University of Peradeniya \\ Sri Lanka
}

\begin{abstract}
Owing to the spectacular colouration, fish species of the genus $\underline{\text { Rasboroides }}$ have a substantial economic value in the aquarium trade of the world. All the species of Rasboroides categorized as threatened fishes. The studies revealed that some species of the genus Rasboroides are having a stable population in the South-western wet zone of Sri Lanka. Osteology of these important species was studied and the findings further support the recently described or re-described species within the genus. One of the important characters of the genus is danionin notch which was only observed in $\underline{R}$. pallidus. This character is always observed in related Cyprinid genera Devario. The presence of danionin notch in $\underline{R}$. pallidus is mystifying since it is independently found in two different tribes of subfamily Danioninae. Further studies ought to reveal the status of this character within the Danioninae.
\end{abstract}

Keywords: Danionin notch, dentary, ornamental fish, Rasboroides pallidus

\section{INTRODUCTION}

Sri Lanka possesses a highly diverse endemic fauna and flora (Myers et al., 2000) and is a reservoir of unique evolutionary history (Bossuyt et al., 2004). During the British rule of the island, several large scale-taxonomic studies on the fishes of Sri Lanka have been carried out. However, the aspects of osteology, ethology and ecology of fishes are handful in Sri Lanka (Costa and Fernando, 1967; De Silva et al., 1977; Kortmulder, 1986; Moyle and Senanayake, 1984; Wickramanayake, 1990). Recently, De Silva et al. (2015) made a comprehensive compilation on freshwater fishes, where almost all reported fishes to date have been included. But that compilation too lacks the aspects of biology and osteology of fish.

Rasboroides vaterifloris (Rasbora vaterifloris) was originally reported in Gilimale, Sabaragamuwa Province of Sri Lanka (Deraniyagala, 1930). Brittan (1972) was the first reviser, who recognized the uniqueness of Rasbora vaterifloris and placed in subgenus, Rasbora (Rasboroides). Kottelat and Vidthayanon (1993) recognized the validity of the subgenus Rasboroides and resurrected to generic rank. Batuwita et al. (2013) resolved the

\footnotetext{
1 Wildlife Conservation Society- Galle, Hiyare, Sri Lanka (Present address: The Society for the Biodiversity Conservation, Kandy, Sri Lanka).

2 Department of Animal Science, Faculty of Agriculture, University of Peradeniya, Sri Lanka

*orresponding author. sbatuwita@pgia.ac.lk.
} 
identity of subdivision of $R$. vaterifloris by recognizing four different species (Deraniyagala, 1958). Previous study of Batuwita et al. (2013) on the genera Horadandia and Rasboroides discusses about a few characters of cranium, suspensorium, and 5th gill arch. Hence, this study discusses descriptive osteology of all congeners of genera Rasboroides.

\section{METHODOLOGY}

Meristic data of specimens were obtained following Batuwita et al. (2013) and staining and clearing procedure, a slightly modified method of Taylor and Van Dyke (1985) were adopted. Osteological terminology followed Fang (2003). Cleared and stained specimens were denoted as c\&s.

\section{RESULTS AND DISCUSSION}

\section{Rasboroides vaterifloris (Deraniyagala, 1930)}

Figures 1A, 2A and Table 1 provide the osteological description of $R$. vaterifloris.

Materials examined. WHT 9701, 1 specimen, 25.5 mm SL (c\&s); Sri Lanka: Ratnapura District: Kalu River basin, Induru stream: Induruwa Forest Reserve, near Gilimale: $06^{\circ} 45^{\prime} \mathrm{N}$ $80^{\circ} 26^{\prime}$ E; WHT 9702, 1 specimen, 25.6 mm SL (c\&s); Sri Lanka: Ratnapura District: Kalu River basin, Adona Stream: Parakaduwa; $06^{\circ} 49^{\prime} \mathrm{N}, 80^{\circ} 18^{\prime} \mathrm{E}$.

Description. Infraorbitals with sensory canals; outer margin of 3rd infraorbital with downward extension; anterior dorsal extension of the maxilla slightly overlaps the premaxilla dorsally; dorsal boarder of operculum even; dorsal outline of lower jaw with a shallow concavity next to symphyseal knob; before the coronoid process of dentary a shallow concavity; superior border of anguloarticular elevated, convex; danionin notch absent; broad coronoid process on dentary; frantoparietal fontanelle present. Abdominal vertebrae12-13; caudal vertebrae16-17; total vertebrae29. Ventral view of the shape of supracleithrum, Lshaped; anterior outline of horizontal limb of cleithrum in ventral view convex; absence of a foramen on anterior wall of horizontal limb of cleithrum; coracoid foramen well-developed; basipterygium broad, not deeply notched. Basihyal with two lateral processes, apophysis narrow; absence of Rasborin process on 4th epibranchial; pharyngeal teeth rows $3(3,4,5-$ $5,4,3)$; pharyngeal teeth with terminal grooves; posterior lateral border of 5 th ceratobranchial deeply notched; uroneural is absent from pleurostyle; parahypural and first hypural fused posteriorly; six hypurals present.

\section{Rasboroides nigromarginatus (Meinken, 1957)}

Figures 1B, 2B and Table 1 provide the osteological description of $R$. nigromarginatus.

Material Examined. WHT 578, 1 specimen, 29.0 mm SL (c\&s); Sri Lanka: Kalutara District: Kalu River basin: Atweltota, $06^{\circ} 33^{\prime} \mathrm{N} 80^{\circ} 17^{\prime} \mathrm{E}$.

Description. Infraorbitals with sensory canals; outer margin of 3rd infraorbital with downward extension; 4th infraorbital greatly reduced; 5th infraorbital absent; anterior dorsal extension of the maxilla slightly overlaps the premaxilla dorsally; outline shape of tip of the 
ascending process of the premaxilla straight; dorsal boarder of operculum with a deep indentation; dorsal outline of lower jaw with a concavity next to symphyseal knob; no concavity before the coronoid process of dentary; superior border of anguloarticular not elevated, truncate; danionin notch absent; narrow coronoid process of dentary; frantoparietal fontanelle present. Abdominal vertebrae12; caudal vertebrae16; total vertebrae28. Ventral view of the shape of supracleithrum: L-shaped; anterior outline of horizontal limb of cleithrum in ventral view convex; absence of a foramen on anterior wall of horizontal limb of cleithrum; coracoid foramen well-developed. Basipterygium broad, not deeply notched; basihyal with two lateral processes, apophysis wide; absence of Rasborin process on 4th epibranchial; pharyngeal teeth in 3 rows $(3,4,5-5,4,3)$; pharyngeal teeth with terminal grooves; no notch on posterior lateral border of 5 th ceratobranchial; uroneural is absent from pleurostyle; parahypural and first hypural fused posteriorly; six hypurals present.

\section{Rasboroides pallidus Deraniyagala, 1958}

Figures 1C, 2C and Table 1 provide the osteological description of $R$. pallidus.

Materials Examined. WHT 11055, 1 specimen, 23.5 mm SL (c\&s); Kalutara District: Kalu River basin: Yagirala, $06^{\circ} 22^{\prime} \mathrm{N} 80^{\circ} 10^{\prime} \mathrm{E}$; WHT 11101, 1 specimen, $17.7 \mathrm{~mm}$; WHT 11113 , 1 specimen, $20.0 \mathrm{~mm}$ SL (c\&s); Galle District: Gin River basin: Kombala-Kottawa forest reserve, $06^{\circ} 06^{\prime} \mathrm{N} 80^{\circ} 20^{\prime} \mathrm{E}$.

Description. Infraorbitals with sensory canals; 1st and 3rd infraorbitals greatly enlarged; outer margin of 3rd infraorbital with downward extension; 4th infraorbital greatly reduced; 5th infraorbital absent; anterior dorsal extension of the maxilla slightly overlaps the premaxilla dorsally; outline shape of tip of the ascending process of the premaxilla straight; dorsal boarder of operculum slightly convex; dorsal outline of lower jaw with a concavity next to symphyseal knob; a shallow depression before the coronoid process of dentary; a broad coronoid process of dentary; superior border of anguloarticular convex, elevated; danionin notch present; frantoparietal fontanelle present. Abdominal vertebrae 11-12; caudal vertebrae 16-17; total vertebrae 28-29. Ventral view of the shape of supracleithrum Lshaped; anterior outline of horizontal limb of cleithrum in ventral view straight; absence of a foramen on anterior wall of horizontal limb of cleithrum; coracoid foramen well-developed. Basipterygium narrow, deeply notched; absence of hypohyal process on the basihyal, apophysis wide; absence of Rasborin process on 4th epibranchial; pharyngeal teeth in 3 rows $(3,4,5-5,4,3)$; pharyngeal teeth with terminal grooves; no notch on posterior lateral border of 5 th ceratobranchial; uroneural is absent from pleurostyle; parahypural and first hypural fused posteriorly; six hypurals present.

Rasboroides rohani Batuwita, De Silva \& Edirisinghe, 2013

Figures 1D, 2D and Table 1 provide the osteological description of $R$. rohani.

Material Examined. WHT 9714, 2 specimens, 25.6-29.5 mm SL (c\&s): Sri Lanka: Ratnapura District: Walawe River basin, Rakwana Ganga tributary: Suriyakanda, 06 $26^{\prime} 59^{\prime \prime}$ N 80³7'10" E, $980 \mathrm{~m}$ above sea level.

Description. Infraorbitals with sensory canals; outer margin of 3rd infraorbital without downward extension; 4th infraorbital greatly reduced; 5th infraorbital absent; anterior dorsal extension of the maxilla slightly overlaps the premaxilla dorsally; outline shape of tip of the ascending process of the premaxilla concave; dorsal boarder of operculum without a deep indentation; dorsal outline of lower jaw with a shallow concavity next to symphyseal knob; shallow concavity before the coronoid process of dentary; superior border of anguloarticular 
straight; danionin notch absent; broad coronoid process of dentary; frontoparietal fontanelle present. Abdominal vertebrae 12-13; caudal vertebrae 17; total vertebrae 29-30. Ventral view of supracleithrum L-shaped; anterior outline of horizontal limb of cleithrum in ventral view convex; absence of a foramen on anterior wall of horizontal limb of cleithrum; coracoid foramen absent; basipterygium narrow, deeply notched; basihyal with two lateral processes, apophysis wide; absence of Rasborin process on 4th epibranchial; pharyngeal teeth in 3 rows $(2,4,5-5,4,2)$; pharyngeal teeth with terminal grooves; no notch on posterior lateral border of 5 th ceratobranchial; uroneural is absent from pleurostyle; parahypural and first hypural fused posteriorly; six hypurals present.

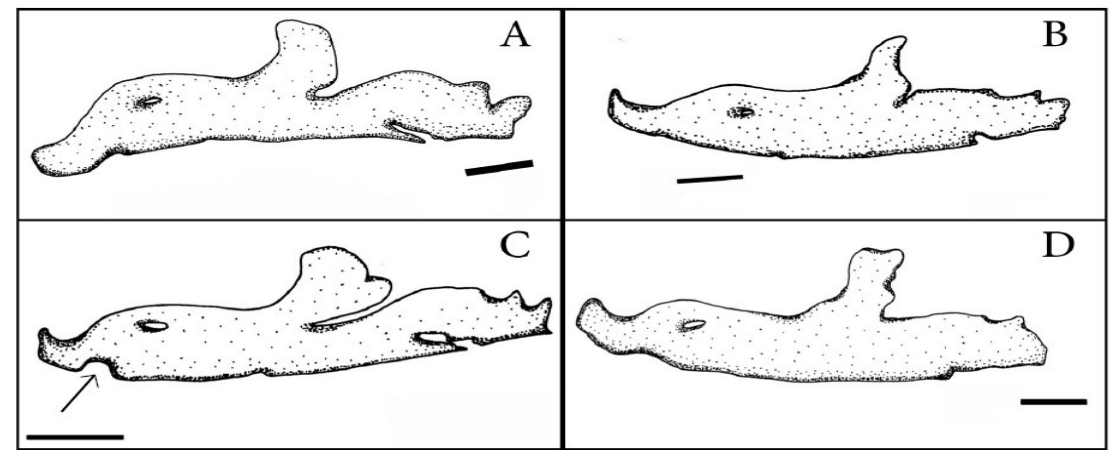

Figure 1. Lateral view of dentary of, Rasboroides vaterifloris (A); R. nigromarginatus (B); R. pallidus (C); R. rohani (D), respectively. Arrow head points danionin notch of $R$. pallidus. Scale bar $0.5 \mathrm{~mm}$.
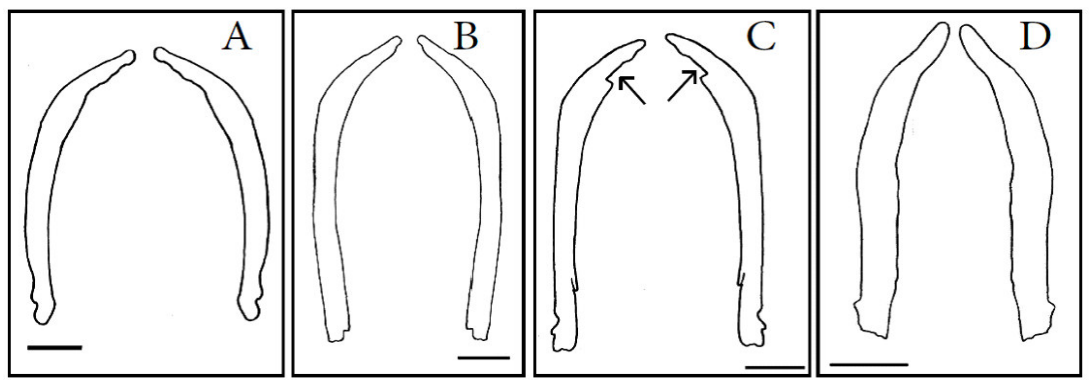

Fig. 2. Ventral view of dentary of, Rasboroides vaterifloris (A); R. nigromarginatus (B); R. pallidus (C); R. rohani (D), respectively. Arrow head points danionin notch of $R$. pallidus. Scale bar $1.0 \mathrm{~mm}$.

Table 1. Pectoral and pelvic girdle characters of, Rasboroides vaterifloris, $\mathbf{R}$. nigromarginatus; $R$. pallidus and $R$. rohani.

\begin{tabular}{|l|l|l|l|l|}
\hline Character & R. vaterifloris & R. nigromarginatus & R. pallidus & R. rohani \\
\hline $\begin{array}{l}\text { Anterior boarder } \\
\text { of cleithrum in } \\
\text { ventral view }\end{array}$ & Convex & Convex & Straight & Convex \\
\hline $\begin{array}{l}\text { Coracoid } \\
\text { foramen }\end{array}$ & Present & Present & Absent & Absent \\
\hline Basipterygium & $\begin{array}{l}\text { Moderately } \\
\text { notched }\end{array}$ & Moderately notched & $\begin{array}{l}\text { Moderately } \\
\text { notched }\end{array}$ & Deeply notched \\
\hline
\end{tabular}


Osteology of Rasboroides species examined in this study showed pronounced differences among the species based on their morphology of cranium and suspensorium, dentary (Figures 1,2), hyoid arch, basihyal, pectoral and pelvic girdles (Table 1). Pectoral and pelvic girdles have distinct differences among species. Morphology of dentary showed distinctly separable characters within the congeners and the consistency of these characters further supports the identity of four discrete species within the Rasboroides.

Kottelat and Witte (1993) placed Rasbora axelrodi Brittan, 1976 in the monotypic genus Sundadanio and considered it to be a member of the danionine lineage because it had a danionin notch in the dentary. However, Fang (2003) stated, that she did not observe a danionin notch in S. axelrodi (in 10 specimens). This describes intraspecific variations and/ or presence of additional species in the genus (Conway et al., 2011).

We examined about eight specimens (c\&s) from the genus Rasboroides from Sri Lanka; only all $R$. pallidus (3 specimens) have the danionin notch (Figures 1C, 2C). However, the presence of shallow depression in $R$. vaterifloris (Figure 2A) has to be verified by further studies. Based on an on-going study of Devario, danionin notch appears to be a well-defined in all the Sri Lankan species (Batuwita et al., pers. comm.). Fang (2003) also concluded that danionin notch is not a Danionin (s. 1.) synapomorphy.

\section{CONCLUSIONS}

The findings of this study confirm the species recognition based on morphology and morphometry by the previous study of Batuwita et al. (2013). The results further revealed that one of the important characters of subfamily Danioninae, the danionin notch occurs also within the Rasboroides, suggesting that danionin notch is not a Danionin (s. 1.) synapomorphy as mentioned by Fang (2003).

\section{ACKNOWLEDGEMENT}

Authors wish to thank Rohan Pethiyagoda (Australian Museum, Sydney) for his guidance throughout this research; Kalana Maduwage (University of Peradeniya) for technical assistance; and the staff at the Postgraduate Institute of Agriculture of University of Peradeniya (PGIA) and the National Museum Colombo. We thank Madura de Silva (Wildlife Conservation Society- Galle (WCSG) and all staff at the WCSG for their assistance. We also wish to extend our appreciation to PGIA for providing Research Facilitation Fund (RFF) which helped to continue this research.

\section{REFERENCES}

Batuwita, S., De Silva, M. and Edirisinghe, U. (2013). A review of the danionine genera Rasboroides and Horadandia (Pisces: Cyprinidae), with description of a new species from Sri Lanka. Ichthyol. Explor. Fres. 24, 121 - 140.

Bossuyt, F., Meegaskumbura, M., Beenaerts, N., Gower, D.J., Pethiyagoda, R., Roelants, K., Mannaert, A., Wilkinson, M., Bahir, M.M., Manamendra-Arachchi, K., Ng, P.K.L., Schneider, C.J., Oommen, O.V. and Milinkovitch, M.C. (2004). Local endemism within the Western Ghats-Sri Lanka biodiversity hotspot. Science. 306, 479 - 481. 
Brittan, M. R. (1972). A revision of the Indo-Malayan fresh-water fish genus Rasbora. T. F. H. Publication, Hong Kong.

Costa, H.H. and Fernando, E.C.M. (1967). The food and feeding relationships of the common meso and microfama in the Maha Oya, a small mountainous stream at Peradeniya, Ceylon. Ceylon J. Sci. 7, 75 - 90.

De Silva, S. S., Kortmulder, K. and Wijeyaratne, M.J.S. (1977). A comparative study of the food and feeding habits of Puntius bimaculatus and P. titteya (Pisces: Cyprinidae). Neth. J. Zool. 27, 253 - 263.

De Silva, M., Hapuarachchi, N. and Jayaratne, T. (2015). Sri Lankan Freshwater Fishes. Wildlife Conservation Society.

Deraniyagala, P. E. P. (1930). The Eventognathi of Ceylon. Spolia Zeylan. 16, 1-41.

Deraniyagala, P.E.P. (1958). Three new cyprinoids, a new catfish and variation among some cyprinoids and an anabantoid of Ceylon. Spolia Zeylan. 28, 129 - 138.

Fang, F. (2003). Phylogenetic analysis of the Asian cyprinid genus Danio (Teleostei, Cyprinidae). Copeia. 2003, 714 - 728.

Kortmulder. K. (1986). Similar behaviour and colour patterns in 3 not closely related Barbus species. Is evolutionary convergence a likely explanation? (Barbus nigrofasciatus Günther, 1868, B. filamentosus (Cuv. \& Val., 1844), B. lateristriga Cuv. \& Val. 1842; Pisces, Cyprinidae). Behaviour. 98, 180 - 212.

Kottelat, M. and Vidthayanon, C. (1993). Borarasmicros, a new genus and species of minute freshwater fish from Thailand (Teleostei: Cyprinidae). Ichthyol. Explor. Fres. 4, 161 - 176.

Moyle, P.B. and Senanayake, F.R. (1984). Resource partitioning among the fishes of rainforest streams in Sri Lanka. J. Zool., Lond. 202, 195 - 223.

Myers, N., Mittermeier, R.A., Mittermeier, C.G., da Fonseca, G.A.B. and Kent, J. (2000). Biodiversity hotspots for conservation priorities. Nature. 403, 853 - 858.

Taylor, W.R. and van Dyke, G.C. (1985). Revised procedures for staining and clearing small fishes and other vertebrates for bone and cartilage study. Cybium. 9, $107-119$.

Wikramanayake, E.D. (1990). Ecomorphology and biogeography of a tropical stream fish assemblage: evolution of assemblage structure. Ecology. 71, 1756 - 1764. 